\title{
Effectiveness of Vipassana Meditation on Communication Skills of Employees
}

\author{
Dr. Pradhan Seema ${ }^{1}$, Dr. V.V. Ajithkumar ${ }^{2}$ \\ \{smprdhn@gmail.com ${ }^{1}$, ajithkumarvv@gmail.com $\left.{ }^{2}\right\}$
}

Consultant Psychologist and Psychotherapist, Fortis Hospitals, Bangalore, India ${ }^{1}$ Associate Professor, Skyline University College, University City of Sharjah, Sharjah, United Arab Emirates ${ }^{2}$

\begin{abstract}
Vipassana meditation (VM) is an ancient Indian meditation technique. Literature review indicates that by practicing VM regularly the meditator develops empathy, equanimity and interpersonal skills leading to better communication ability. A quantitative study was conducted on meditator and non-meditator employees comprising of 240 participants each by using a developed Behaviour Measure Scale (BMS) to measure the above mentioned variables. Statistical analysis was done using SPSS Ver. 20.0. The results showed that meditator group respondents scored statistically higher than non-meditators on empathy, equanimity and interpersonal skills. In addition to the quantitative study, a qualitative study was conducted by interviewing 10 meditator employees. The participants reported enhancement in their communication skills after practicing VM leading to better relationships at work as well as at home. This quantitative and qualitative study showed that practicing VM enhances empathy, equanimity, and interpersonal skills paving the way for better communication ability. This helps the practitioner have harmonious and effective communication at work and in his/her life eeds to summarize the content of the paper.
\end{abstract}

Keywords: Communication ability, Empathy, Employees, Equanimity, Vipassana Meditation

\section{Introduction}

The word communication originates from the latin word 'communicare' which means "to make common to many, to share, to impart" [56]. It is an exchange of information, feelings and perceptions that facilitates an understanding, sharing of experiences, thoughts and resources. Communication is needed at each and every step of our life and effective communication is vital for the achievement of desired purpose. It could be verbal as well as non-verbal. It is difficult for any individual or organization to progress without good communication skills. When the communication lacks clarity it becomes vague and distorted leading to confusion and misinterpretation amongst friends, family members and colleagues alike and many issues remain misunderstood and unresolved. Clarity and openness in communication helps to develop a sense of warmth, closeness and tolerance.

Human beings have an intrinsic desire to interact and communicate with others and this is a fundamental and deep seated need. In each and every phase of life right from the cradle to the grave we are constantly communicating with others, either verbally or non-verbally, to convey our ideas, thoughts, emotions, needs and desires. Further, it is important that the 
communication is effective otherwise company executives, business people, members of teams and even those applying for jobs will not be able to reach their goals. This effectiveness of communication is required whether the interaction is between two people, within a group as in one-to-many communication or even in society at large as in a broadcast setting.

The importance of communication skills as a preventive and therapeutic tool started to surface between 1970 and 1980. The contribution of skilled interpersonal communication to success in both personal and professional contexts is now widely recognised and extensively researched. According to Carl Rogers [65], communication suffers when the people are emotionally disturbed as their unconscious and unmet longings and desires surface in their communication and tend to create distorted communication patterns. Their interpersonal relationships are adversely affected due to this and they also suffer within themselves [24].

Psychotherapy helps an individual achieve, good communication within himself or herself. After which the person is able to communicate effectively and more freely with others. Rogers felt that 'listening' to the client is critical to "good communication". Rogers [65] further added that, "through my experience in counselling and psychotherapy, I've found that there is one main obstacle to communication: people's tendency to evaluate. Fortunately I've also discovered that if people can learn to listen with understanding, they can mitigate their evaluative impulses and greatly improve their communication with others".

Thomas Gordon [79] was instrumental in enabling people to communicate effectively on their own and encouraged them to learn active listening skills and thus took communication skills out of the psychotherapist's office. He started to train teachers, parents, and business leaders; his influence and efforts showing their positive impact in schools, international negotiation and the growing mediation movement, in corporations as well. Interpersonal communication is vital for carrying out any business. The importance of skilled interpersonal communication in achieving success in business and personal spheres has been recognized widely and has also been the topic of extensive research [33]. Communication in business should be done clearly, efficiently, and accurately since it is an indicator of the company's level of professionalism both within and outside the organisation.

Good communication skills are essential for an individual as well as for an organization. The future of any organization largely depends upon its channels of communication as this helps to facilitate partnerships, promotion of sales and services and gives information about the organization. It can have a great impact on a company's reputation and credibility, and will definitely say a lot about its level of professionalism. Business itself is a form of interpersonal communication as all the parties involved with the business such as employees and administrators, buyers and sellers need to communicate effectively for business promotion. Technical and theoretical knowledge is essential but in order to get results it also needs to be coupled with effective communication. It is important that professionals in all fields make efforts and utilise every opportunity to communicate their thoughts and vision to members of their team, their superiors, clients and customers so that there is a clarity of purpose and cohesion in action.

Effective interpersonal communication is a two-way exchange which requires active listening, receiving the information accurately and replying back with clarity. This kind of congruence in communication requires personal courage and a secured feeling about oneself. This originates from being confident and aware about oneself. These are perquisites for effective inter personal communication.

Theoretical and empirical evidence indicates that an important factor for different aspects and areas of youth adjustment is the communication between the youths and parents. Marta [50] in research on parent-youth communication has reported that openness in 
expressing views, feelings and ideas as well as managing conflict effectively are vital ingredients of the communication process. It leads to reduction in the tendency to engage themselves in risky behaviours like substance abuse [62], [64]. On the other hand there is an increase in well-being, self-esteem and coping [37]; and an improvement in overall 'socialemotional' adjustment [71], [72].

When there is a clarity in parental communication there is less ambiguity and this is important for effectively conveying and transmitting the messages as well as the expectations, values and goals to children. Research indicates that it leads to improved adjustment in youth and children [64]. When communication is not clear, vague or left unresolved, it tends to create confusion amongst the family members and this leads to misinterpretation of the communicated messages. On the other hand openness fosters a sense of togetherness, belonging, tolerance and warmth and facilitates emotional sharing. Families, where expressing opinions openly is encouraged, tend to foster individuals with an ability to demonstrate and respond to a wide range of feelings. It helps to reduce the psychosocial risk for the youth. Problem resolution skills and tolerance for disagreement enable conflict management to be handled in a positive and adaptive manner [84]. According to Walsh [84] clarity, openness, and collaborative problem solving are the three most important and critical aspects of communication for family resilience. Montemayor [52] observed that within the family, communication and problem solving skills form the foundation and critical component of the interaction between parents and children.

Recently, nonviolent communication [66] also called compassionate communication has been put forth as an aid for communication effectiveness as it includes expressing feelings and needs in a natural way. Decety and Jackson [15] in their study on empathy research point out the importance of being able to verbally express empathy and they explore the communication skills required to verbalize empathic responses and the effects of the use of these verbal empathic expressions. They concluded that conversation helps to develop empathy by allowing us to learn about shared emotions and experiences. It was Rogers, [65] who first highlighted the crucial role of empathetic communication in the psycho-therapeutic field. In fact, this has been recognized as an important ability in many other 'helping' professions [26]. For this reason currently there are a number of 'empathy training programs' and 'communication skills' trainings presenting varied techniques and constructs [10], [77].

The same concept is put forth by Vipassana meditation (VM). VM practice helps enhance the human values which are universal such as empathy, compassion, tolerance, peace, harmony as well as love and good will [12]. This is particularly useful when faced with challenging situations such as addressing disciplinary issues, disagreements and clash of interests, instead of reacting with anger or withdrawal causing undue escalation or break in communication. This ancient meditation technique reinforces the value of compassion and collaborative adaptation by changing deep seated personal behaviour patterns leading to improvement in interpersonal relationships and communication through non-reactivity. The present study, attempts to measure the effect of VM on these aspects of communication using quantitative and qualitative methods.

\section{Objectives of the study}

\subsection{Quantitative Objectives}


What is the effect of Vipassana Meditation on employees' communication abilities. Here the communication abilities were quantitatively measured with reference to

- Interpersonal skills

- Empathy

- Equanimity

- $\quad$ Self-Awareness

- $\quad$ Self-Confidence

\subsection{Qualitative Objectives}

Collect qualitative evidence of the effect of VM on employees' communication abilities.

\section{Literature Review}

\subsection{Vipassana Meditation}

Gautam Buddha rediscovered and introduced Vipassana Meditation (VM) or insight meditation, 2500 years ago, for the benefit of one and all. It is a choice-less observation, as a spectator of what is happening inside your own body in the form of sensations moment by moment. Vipassana is defined as to see the things as they are, again and again, in a special way [28]. Vipassana meditation has three parts namely, Anapana or awareness of natural breathing, Vipassana and Metta Bhavana which is universal love and compassion for all beings.

Vipassana is also called as "insight" meditation, as it brings insight into the functioning of the human psychic. Insight meditation draws attention to mental and physical phenomenon as they occur over time. This practice leads to a systematic process of observation of sensory inputs of all the occurring phenomenon and realization of their transitory and impermanent nature. This insight form of the practice helps us to understand the futile attachment to 'I' and liberates us from suffering by facilitating sustainable intra-psychic change [54]. This is the practice of a "clear and single-minded awareness of what actually happens to us and in us at the successive moments of perception" [55]. This choice less observation paves the way to observe and attend to all the stimuli equally without any preference for anyone of them.

Vipassana enables us to reach into the unconscious mind and experience the sensations as a spectator without reacting to them thus allowing them to pass without incident, ridding the mind of negative thoughts and memories. Due to this, one's mental phenomenon no longer have control over his/her personality and behaviour. This helps the individual slowly but surely come out of one's uncontrolled and unaware psychic phenomenon as the change happens at the experiential level [55]. VM helps to transform the self through self-observation by increasing equanimity, awareness and mental peace [30].

Vipassana meditative technique involves the scanning of sensations throughout the body in an iterative and cyclic fashion. It is a mind-body phenomenon. This self-observation enables the practitioner to develop an ability to quieten the mind by getting out of compulsive thought patterns. In this manner a slow, cumulative change can be brought about by practicing VM as individuals start building their lives around new sources of well-being. There is a sense 
of aliveness that is marked by a willingness to invest in the personal and real self ardently [22].

Mindfulness is thought to promote attunement, connection, and closeness in relationships, as well as the capacity for compassion and connectedness [41], [46]. This traditional wisdom suggests there is a link between mindfulness and human interpersonal relationships; recent research has begun to explore this link. Much of the recent research on mindfulness can be applied to interpersonal situations. Research also suggests that psychological well-being plays a role in healthy relationships [21], [23]. Mindfulness has been linked with several aspects of individual psychological well-being [60]. In correlational studies, Brown and Ryan [9] found mindfulness was associated with lower levels of depression, self-consciousness and hostility, and higher levels of positive affect and life satisfaction. They also found positive associations with openness, relatedness, and interpersonal closeness, all traits that are thought to be important in forming and maintaining satisfying

relationships.

\subsection{Vipassana Meditation and Communication}

Before starting Vipassana meditation, which is a 10-day residential course, students have to undertake and observe the following five precepts and refrain from performing harmful actions.

- Abstention from lying

- Abstention from stealing

- Abstention from sexual misconduct

- Abstention from killing

- Abstention from taking any intoxicants

It is compulsory to ensure that one observes these five precepts. Following these precepts helps to develop 'sila' and calm the mind, and is a prerequisite for Vipassana meditation practice. Sila is one of the pillars of 'astangmarg' or 8-fold noble path, the remaining two are Samadhi and Panna. According to Buddha's teachings [34], for progressing on the noble path respecting these 3 pillars and their 8 components is essential. They are schematically shown in Figure 1 below. 


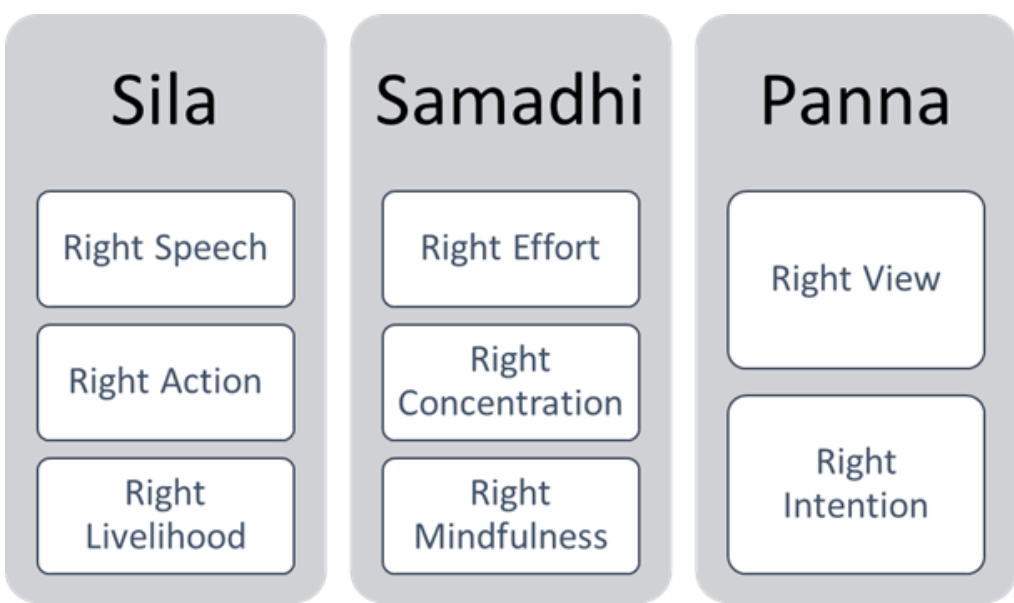

Fig 1: The Three Pillars of Ashtang Marg: Eight Fold Noble Path

According to Buddha, "Those who practice right speech speak the truth and are steadfast in truthfulness, trustworthy, dependable, and straightforward with others. They reconcile the quarrelling and encourage the united. They delight in harmony, seek after harmony rejoice in harmony, and create harmony by their words. Their speech is gently, pleasing to the ear, kindly, heart-warming, courteous, agreeable and enjoyable to many. They speak at the proper time, according to the facts, according to what is helpful, according to Dhamma and the code of conduct. Their words are worth remembering, timely, well-reasoned, well-chosen and constructive" [8].

Vipassana purifies the deeper unconscious roots, of conflict, serving as an important adjunct to the cognitive cleansing of active listening which suggest tools on how to implement Buddha's right speech, one out of the eight fold noble path (or asthangmarg). This insures that messages sent are the same messages received, making communication and its purposes more efficient. VM creates compassion and empathy in the practitioner which is a prerequisite for good communication skills. A vast empirical literature indicates that empathy contributes to warm, close interpersonal relationships and inhibits interpersonal aggression [20].

By tuning into direct experience, Vipassana addresses what is happening by remaining at the level of sensations. VM trains one to be aware of bodily sensations and at the same time remain equanimous towards them. This empowers the individual in such a way that life situations cannot get the better of the person. A mindful communicator operates at two levels; the unconscious level of the mind where involuntary and automatic reactions are born and at the conscious verbal level. At the unconscious level, misunderstandings are recognised at their source and nipped in the bud, through equanimity towards changing situations, before they can launch a storm of perpetuating reactions. Secondly, being aware of physical sensations such as dry throat, stomach knots and blood rush allows for advance warning of conflict, giving time to reassess the urge to speak or react impulsively and reorient the person towards a more conscious and reasoned response.

Just as in mindfulness practice we learn that the solution to overcoming feelings of attachment and / or aversion is merely to observe them acceptingly until they fade away, similarly, merely listening and acknowledging the other person's experience is often the 'solution' to finding a better way to communicate with others. The tendency to react to an 
emotionally charged situation or statement by evaluating it from one's own point of view is a major barrier to better interpersonal communication [65].

Initial evidence indicates that even though mindfulness is an individual and subjective quality, interpersonal behaviour and quality of dyadic and workgroup relationships are affected by it [31]. Beckman et al., [5] have reported improvement in communication quality along with increased awareness and open listening as well as reduction in evaluative judgement of others due mindfulness training and dispositional mindfulness among health care practitioners. Long \& Christian [49], observed in a pair of studies that higher levels of dispositional mindfulness and mindfulness training result in improved relationships because of better self-regulation leading to moderated responses to perceived injustice, reduction in negative emotion, rumination and negative action motivated by a desire for retaliation. Also, a better client-rated relationship quality was observed by Beach et al., [4]. Reb et al. [63] found that leaders' dispositional mindfulness was associated with more favourable subordinate attitudes and behaviours via improved relationship quality.

Good et al., [31] discussed how mindfulness effects the domains such as cognition, emotion behaviour and psycho-sociology that impact work place performance, relationships and well-being. Mindfulness has an effect on impulsivity and self-maturity [73], [74], [14]. It is negatively associated with neuroticism [27] and correlates positively with conscientiousness. Studies have reported increases in compassion due to mindfulness [6], [81]. Mindfulness makes it possible to develop an attitude of non-attachment and thus facilitates the awareness to be unbiased. Practicing mindfulness regularly, enhances the attribute of nonattachment in the personality of the practitioner [80]. This non-attachment, manifests itself as the lack of fixation on images, sensory objects or ideas and nor a desire or pressure to mould or change circumstances or experiences [68]. It is for this reason that non-attachment has been singled out as one of the principal adaptive action mechanisms causing improvement in wellbeing through mindfulness interventions [36], [78].

Mindfulness fosters empathy and compassion which in turn helps to improve relationships. This was shown by a number of studies, such as research by Dekeyser et al., [16] which supported an association between trait mindfulness and empathy. Further, a study by Condon et al., [13] on individuals participating in a MBSR program showed that they exhibited greater compassion than wait-group controls, such as when a colleague entered a full waiting room on crutches, more than $50 \%$ of those who had completed the MBSR program offered their seats as compared to less than $20 \%$ of the controls.

According to Atkins and Parker [2] compassionate behaviour is facilitated by mindfulness meditation and instead of reacting automatically, employees start responding to situations consciously leading to increased cooperation, support and trust. Kabat-Zinn [42] documented that mindfulness helps us to refrain from impulsive and destructive reactive behaviour by fostering an ability to observe our emotions and thoughts like a spectator in a detached manner. It helps us to get out of 'fight or flight' response and handle stressful situations with confidence.

Metta Bhavana which is a component of VM is about dealing with all other living beings with love and compassion, in the context of inter-personal communication, this is advocating exactly what nonviolent communication (or NVC) otherwise called compassionate communication advocates [66]. To be able to listen with compassionate acceptance to what is being said, whether we agree with it or not, it is necessary to remove our own prejudices, evaluations and judgments. To accomplish this means emptying our minds of the incessant dialogues based on attachments, dislikes and aversions. Vipassana training would therefore be a good way to enhance our own communication abilities and skills. A study by Jinadasa [38] 
concluded that Buddhist philosophy expounds on many concepts which, if followed, can help build and develop facets of public relations which in turn is a key factor to foster today's media and communication industry.

In the work place, VM is reported to be effective in enabling better communication, stress management, compassion and empathetic behaviour, altruism and increase in productivity [35], [75], [76]. Kadziolka et al. [43] reported that it fosters self-regulation of stress. Earlier studies have documented that VM practice facilitated group efficiency, team spirit, consensus decisions, self-motivation in the employees [70]. There was an improvement in employees' interpersonal relations and mental health. Practice of VM facilitated harmony and industrial productivity in the work place [32]. There was a reduction in labour problems and absence of strikes in the company. Employees reported reduction in anger, greater tolerance and harmony. Joshi [40] has reported a decrease in hatred, short-temperedness, fatigue, jealousy, negativity, and confrontation because of jealousy, ego, guilt-feelings, etc. Parihar [57] reported that VM enabled government officers' face their professional and personal lives with positivity and confidence. Similarly, Agrawal and Bedi [1] reported that there was an improvement in the interpersonal relationships of the Delhi Police Trainees after practicing VM.

Research indicates that in case of supportive communication, cognitive-affective processes are mainly influenced by mindfulness [39]. Jones [39] examined positive influence of self-reported abilities of mindfulness facets (describing, observing, non-judging, aware acting, non-reacting)in terms of less person-centred supportive messages and cognitive factors, namely, empathy and active listening in case of college students with little or no meditation experience. Empathy and active listening mediated the relationship between 'describing' and 'observing' mindfulness facets and the perceptual outcome measures in this study. The results suggested that mindful observing and describing positively predicted empathy and active listening The 'describing ' and 'observing' mindfulness facets positively impacted performing reappraisals while 'non-judging' facet negatively impacted empathy and active listening.

Mother-adolescent communication could be improved by mindful parenting as it helps to improve the affective quality of the relationship. Mindful parenting ensures that parents listen to adolescents with an open mind without automatic dismissal of their views and this in turn is perceived by the adolescent as an acceptable behaviour rather than being constantly faced with a controlling parent [48].

In addition to helping the individual, mindfulness and self-compassion skills could impact and improve couple functioning as well [69]. Many studies on the relationship quality of intimate partners' shows that mindfulness of the partners has a positive effect on the partnership through the ability to give greater attention to the partner, better communication, reduced emotional reactivity and better conflict handling and greater expression of compassion and empathy. Salient among these are:

- Study by Quaglia et al., [61] and Wachs \& Cordova, [82] showed that trait mindfulness enhanced relationship quality.

- Study by Saavedra, Chapman, \& Rogge, [67] indicated higher relationship stability because of trait mindfulness.

- Carson et al., [11] reported that couples who participated in mindfulness training exhibited higher relationship satisfaction, closeness, and partner acceptance than controls who did not take mindfulness training. 
- Wachs \& Cordova [82] and Barnes et al., [3] stated that mindfulness improves relationships between partners through sustained capacity to communicate emotional information.

- Saavedra et al., [67] and Wachs \& Cordova [82] reported that trait mindfulness helped the partners to manage conflict by refraining from exhibiting anger and hostility.

- Dickinson et al., [18] in a study related to aphasia reported that the person's anxiety scores were effectively reduced due to mindfulness programme. The changes and improvement in language were evident in 'confrontation naming tasks'

VM and Metta Bhavana are the two methods by which conflict resolution may be achieved [86]. Metta Bhavana or loving kindness helps one to develop compassion, friendliness and kindness to all beings which helps to contribute towards conflict resolution as the barrier to conflict resolution is emotional rigidity and reactivity of the parties involved. $\mathrm{VM}$ can help in conflict resolution as it facilitates present moment awareness and focus with clarity and awareness of the problem and at the same time being flexible and open to seeking out solutions by remaining equanimous. Equanimity helps to inculcate a shift in the perspective leading to a kind of detachment towards the experiences that are ongoing [83]. This shift in the perspective helps to widen one's perspective on different experience, and the individual is able to respond to the present moment and in the 'here and now' skilfully [17]. Also, VM helps us to understand the concept of 'annica' or impermanence of all phenomena, which increases sympathy and tolerance to the concerns and views of others. In another study the findings supported that the type of conflict strategy chosen by the people is predicted by mindfulness aspects [45].

Psychologist Rogers [65] describes interpersonal relationships (IR) as - "assuming a minimal mutual willingness to be in contact and to receive communications, we may say that the greater the communicated congruence of experience, awareness, and behaviour on the part of one individual, the more the ensuing relationship will involve a tendency toward reciprocal communication with the same qualities, mutually accurate understanding of the communications, improved psychological adjustment and functioning in both parties, and mutual satisfaction in the relationship."

Meditative practices help to develop qualities which have a bearing over interpersonal relationships in terms of closeness, trust and empathy as well as compassion [85], [44]. This happens as one develops non-reactivity by choice-less observation of emotions and thoughts which helps the individual to come out of blind reactive patterns of behaviour [53]. Healthy interactions are facilitated as individuals refrain from aggression, angry outbursts and saying hurtful things [30]. Responding adaptively without reacting helps better handling of situations which are socially conflicting [25].

Thus introducing meditative practices in organisations would be particularly beneficial as managing any organisation is inherently relational and one of the important relationships at work are between managers and supervisors [19]. Also, effective communication, coordination and cooperation between group members is very important for group work in any organisation [51]. 


\section{Methodology}

The research design used in this study was After-Only with Control Design [47]. In order to empirically test the research hypothesis, a questionnaire related to the behaviour and personality of employees was designed. The instrument also had a section to collect demographic details of respondents.

Sample data collection was done for both quantitative and qualitative analysis.

\subsection{Quantitative Study Context and Sample}

The employees from different organisations enrol at the Bangalore Vipassana Meditation Centre, India for undergoing a 10-day VM course. They were the subjects for this study. The sampling technique used for collecting the data was judgement sampling. The selection criteria ensured that the subjects were regular practitioners of VM. The instrument was administered for data collection to the following two groups of employees, namely,

1. Non-meditators (control group) - employees coming to attend a VM course for the first time.

2. Meditators (experimental group) - employees who are practitioners of VM and have already completed at least three 10-day Vipassana courses.

Employees attending the course came from different cross-sections of society. Participation in the study was voluntary. The questionnaire included clear instructions on filling it up. Participants had sufficient time ( $\sim 5$ hours) to complete the questionnaire.

The questionnaire, Behaviour Measure Scale (BMS) was designed and pilot tested.

The responses were captured by using a 5-point Likert scale. $1=$ "Never or very rarely true" to 5= "Very often or always true". Dimension reduction was achieved by employing an exploratory factor analysis (EFA) with Principal Component Analysis (PCA) and varimax rotation. The factors obtained were validated by performing a confirmatory factor analysis using R program for this purpose (Pradhan \& Ajithkumar, 2017). Completed questionnaires with 22 questions were collected back prior to the start of the course (Pradhan et al., 2016).

For final analysis a total of 240 samples each were collected from non-meditator and meditator groups after filtering out incomplete responses.

Both the groups were matched on the demographic factors as shown in Table $\mathbf{1}$ below:

Table 1. Demographic Composition of the Two Groups

\begin{tabular}{|l|l|l|}
\hline Demographic Factor & Non-Meditator Group & Meditator Group \\
\hline Age & Mean $=38.28$ years & Mean $=39.31$ \\
\hline Gender & Male $\%=57.5 \%$ & Male $\%=57.1 \%$ \\
\hline Marital Status & Married $\%=63.3 \%$ & Married \%=56.3\% \\
\hline Educational Level & Graduates \& above $\%=90 \%$ & Graduates \& above $\%=91.3 \%$ \\
\hline Dominant Work sector & $\begin{array}{l}\text { Services \& Software } \% \\
=57.1 \% \text { Services \& Software } \% \\
61.7 \%\end{array}$ \\
\hline Work Position Held & Middle \& Senior $\%=53.8 \%$ & Middle \& Senior $\%=54.9 \%$ \\
\hline
\end{tabular}

The questionnaire had items like 
Factor 1= "I am able to communicate clearly with people around me."- Interpersonal skills Factor 2="When interacting with others I consider their feelings and expectations" - Empathy Factor 3="In stressful situations I am usually the one comforting other people" - Equanimity Factor 4= "I look for ways to relax when I am stressed."- Self-Awareness

Factor 5= "I am open to new ideas and new information." - Self-Confidence

\subsection{Quanlitative Study Context and Sample}

Overall 23 meditator employees who have completed minimum three 10-day Vipassana meditation courses were interviewed to understand the overall changes they have experienced in their behaviour and personality after practicing VM.

\section{Analysis of Data}

\subsection{Quantitative Analysis}

Quantitative data analysis was performed by employing SPSS Ver. 20.0. Analysis was carried out for determining the reliability and sampling adequacy for performing factor analysis. The results are shown in Table 2 below.

Table 2. Reliability and Sampling Adequacy

\begin{tabular}{|l|r|}
\hline Cronbach's Alpha based on Standardized Items - 22 items & 0.846 \\
\hline Kaiser-Meyer-Olkin Measure of Sampling Adequacy. & 0.846 \\
\hline
\end{tabular}

The scores obtained by non-meditator group (N) and meditator group (M) on the five factors identified were computed and the group statistics are as shown in Table 3 below.

Table 3. Factor Scores and Group Statistics

\begin{tabular}{|c|c|c|c|c|}
\hline Factors & $\begin{array}{c}\mathrm{N}=240 \\
\text { (per group) }\end{array}$ & $\begin{array}{l}\text { Mean } \\
\text { Scores }\end{array}$ & Std. Deviation & $\begin{array}{c}\text { Std. Error } \\
\text { Mean }\end{array}$ \\
\hline \multirow{2}{*}{$\begin{array}{l}\text { Inter-Personal } \\
\text { Skills }\end{array}$} & Non-Meditators & 19.104 & 3.027 & 0.195 \\
\hline & Meditators & 20.059 & 2.603 & 0.168 \\
\hline \multirow{2}{*}{ Empathy } & Non-Meditators & 18.792 & 3.069 & 0.198 \\
\hline & Meditators & 19.978 & 2.744 & 0.177 \\
\hline \multirow{2}{*}{ Self-Awareness } & Non-Meditators & 13.733 & 3.105 & 0.200 \\
\hline & Meditators & 16.124 & 2.482 & 0.160 \\
\hline \multirow{2}{*}{ Equanimity } & Non-Meditators & 16.042 & 3.303 & 0.213 \\
\hline & Meditators & 18.729 & 2.914 & 0.188 \\
\hline \multirow{2}{*}{ Self Confidence } & Non-Meditators & 11.979 & 1.995 & 0.128 \\
\hline & Meditators & 12.750 & 1.658 & 0.107 \\
\hline
\end{tabular}

The Independent samples t-test results for Behaviour Measure Scale are reported in Table 4 below. The results indicate that the mean difference in scores between the groups is 
statistically significant as $\mathrm{p}<0.05$ for all the factors. Negative t-test values indicated that the meditator group's mean scores were higher than the non-meditator group for all the factors.

Table 4. Independent Samples t-Test Results

\begin{tabular}{|c|c|c|c|c|c|}
\hline \multirow{2}{*}{ Factors } & \multicolumn{5}{|c|}{$\mathbf{t}-$ Test for Equality of Means } \\
\cline { 2 - 6 } & $\mathbf{t}$ & $\mathbf{d f}$ & $\mathbf{p}$ Value & $\begin{array}{c}\text { Mean } \\
\text { Difference }\end{array}$ & $\begin{array}{c}\text { Std. Error } \\
\text { Difference }\end{array}$ \\
\hline Inter-Personal Skills & -3.706 & 478 & $<0.001$ & -0.955 & 0.258 \\
\hline Empathy & -4.465 & 478 & $<0.001$ & -1.186 & 0.266 \\
\hline Self-Awareness & -9.317 & 455.859 & $<0.001$ & -2.391 & 0.257 \\
\hline Equanimity & -9.452 & 478 & $<0.001$ & -2.688 & 0.284 \\
\hline Self Confidence & -4.604 & 462.547 & $<0.001$ & -0.771 & 0.167 \\
\hline
\end{tabular}

\subsection{Quanlitative Analysis}

Qualitative analysis highlighted the many benefits experienced by the 23 respondents as summarised below.

Many of the interviewees reported that they obtained significant benefits connected with their performance at work and in their relationships with their work colleagues. Some of the salient benefits that were reported are enumerated below:

- Ability to work longer hours without getting fatigued

- $\quad$ Being honest at work about what could be accomplished, ensuring less anxiety

- $\quad$ Lower stress levels in spite of being in a high pressure environment

- Became a team player and more acceptance of others' differences

- Became more receptive to others' suggestions

- Stopped making decisions driven by self-ego but rather in a spirit of team goals

- No longer a control freak, but more empathetic relationship with colleagues

- $\quad$ Became more patient with their associates - this helped in business

- $\quad$ Reduced being reactive to changes at work and became more accepting of such changes

The interviewees also reported that they experienced changes in their own personality and behaviour as well as in their relationships with friends and family members. Some of the significant changes reported are enumerated below:

- $\quad$ Reduced shyness and increased self-confidence

- More friendly and open to people

- Increased ability to communicate feelings with family members

- Higher interest in the activities of family and friends, greater participation in them

- $\quad$ Facing life events and situations with a positive attitude

- Greater acceptance of events happening and less stress in difficult situations

- Greater sharing and trust in relationships with friends and family members

- $\quad$ Reduced tendency to become angry and instead be more patient with others 
- Tendency to act out of a sense of revenge replaced with accepting them and their differences leading to better relationships

- Able to handle uncertainty and change without getting anxious and worried - nonreactive

- Abusing family members through verbal and physical means reduced - better relationships with spouse and children.

Out of the meditator employees some were interviewed by conducting face-to-face interviews. Brief snapshots of the comments of 10 employees on the changes in their communication ability are reported in a verbatim fashion for reference below.

Meditator $1:$ [ Male, 34 years, completed $7-10$ day courses]

"I was angry, short tempered and introvert and shy person and took toxic substances. VM made me very strong. Addiction stopped completely after third VM course. My upbringing is not good. 'There was domestic violence and got beatings'. Now I am able to communicate. I have become more confident and not shy anymore. Now I am more open and friendly with people and accept others without judging them. Earlier I did not want to be close to people. Now I have become friendly and open to new people. Become more accepting of others without judgement. Also I used to be very strict with myself and used to get angry with myself. After VM I have started accepting the way I am. Stress is reduced a lot.

Before I was career oriented person. I have been a 'Target achiever' and I never gave complete information; only gave the information that will get me the work. Now honesty in my interactions has increased and I am able to take fast and proper decisions. My productivity, quality of work (recruitment job) is improved, has become wholesome and I do not cheat anymore."

Meditator 2 : [ Male, 44 years, completed 5 - 10 day courses]

"I have a fantastic relationship with colleagues. Respect for individuals has increased and don't force them to do work. Trustworthiness is increased. Concentration has increased and I have become more mindful. Thought clarity has become excellent. Do not consider stress as stress anymore. External situations, nothing can perturb me. I have become very strong internally. I am able to handle the situations well and better even in a foreign country. Excellent relations with my family and friends. Married life is good and happy. Wife is also a Vipassana meditator. She supports me a lot. Earlier I was very introverted. Now I have become open to other people and situations. Don't force anybody. I have become more selfassured."

Meditator 3 : [ Male, 32 years, completed 5 - 10 day courses]

"Family relations have improved in spite of economic problems. Understood how to give respect. I have become strong and at the same time more flexible, adjusting, able to understand relations better. I have started to understand myself better -what I can do and what I cannot do, my short comings. Earlier used foul language. Now have learned to talk properly and use better language and I am careful with my words. Stress and anger are reduced and equanimity is developed. Good relations with colleagues and friendly relations with my students." 
Meditator 4 : [ Male, 44 years, completed 4 -10 day courses]

"My self-confidence is increased and I have become better at handling difficult situations. I have become a better person in all different areas like managing stress, interpersonal relationships. My family has spiritual orientation and all family members are Vipassana meditators. Family relationships are very good and everybody practices equanimity knowing that nothing is permanent. Peaceful and understanding relations prevail amongst my family members. I treat my wife as my equal partner. I handle my children with love and calmness.My mindfulness is increased and I have become more mindful."

Meditator 5 : [Male, 34 years, completed 9 -10 day courses]

"Before doing VM I was short tempered. Now I have become calm and I am able to understand the reality of the situation better. There is a progress in handling the stress and does not get affected by it as earlier. Handling of the situation is improved. Concentration has improved. Relationships have become good. In social situations I am calm and deal with them confidently. Still somewhat shy but after doing VM shyness is decreased."

Meditator 6 : [Female, 32 years, completed $4-10$ day courses]

"In my work place I am less reactive. VM has made a difference. I am able to put up with nonsense from people but still feel awkward and get shaken up. Nevertheless I am able to quickly come out of hurt and disappointment. Ego is still there. At the same time I have become more functional at the work place. My decision making has improved and I think of others also. Have become more equanimous. Even if I get angry less verbal actions are there. Awareness is more so anger is reduced. Less use of harsh words is happening. Say out of 10 three are avoided. Communication has become more truthful. My relationship with husband has gone through turmoil in the past few years. Now it is improving. Personally have become better. There is a decrease in selfish tendencies. Thoughts of others, how it will affect others comes to mind. Consideration for others is increased".

Meditator 7 : [Male, 25 years, completed 3 - 10-day courses]

"Personally my temper has gone down and my concentration has improved. Level of confidence fluctuates- sometimes up sometimes down - depending upon situation and people. Since I have started practicing VM my inferiority complex is reduced. Earlier I used to bother about what people have said about me. Now the time duration is decreased.

Regarding conversing with people I find all conversations pointless and therefore I don't participate. But I have deeper one to one conversations individually with them. Quality of friendship has become better. I cannot deal with superficial conversations. Earlier I used to feel very sad. Now sadness is diminishing and genuineness is increasing. I talk to people in a manner that is suitable."

Meditator 8 : [Female, 66 years, completed 3 - 10-day courses]

“At personal level my 'quality of talking' has become better. There is an understanding of 'impermanence'. 'How it has helped me to get insights and a different way of looking at 
things!' In VM understanding happens very fast. I have become more comfortable with myself.

Socially, I have become more accepting of others views and become more equanimous. Also, I am able to withdraw from the situations amicably. Family relations have improved over the years and after VM have learned to let go."

Meditator 9 : [Male, 28 years, completed 5 - 10-day courses]

"Personally speaking before VM my ego was too much. 'If somebody said something about me I used to go and hit that person. I was almost like a goonda'. I wanted to be the centre of attraction. 'I used to make fun of everybody; but nobody should make fun of me'. After my first VM course I felt that I got what I was searching for. I was happy that I found the path to come out of aversion, craving etc. I changed completely. After VM I have taken a U-turn in life. Now 'Balance in life' has come and mentally I am at peace. I don't react - the main thing the core thing I got is - not to react. Mind is in my control. Before this mind took the role of 'Master of body'. I am at peace. If somebody says something (passes a comment) I tell them not to do that. When I show anger I don't have any anger inside. I feel that people are hurting themselves by doing stupid things - like troubling me. I feel compassion for them.

After VM I feel that we have to accept everything. Earlier I wanted to have only fun- parties, movies, chitchatting etc. Now I work to fulfil basic needs, live comfortably and spend time in fruitful activities. I am more tolerant with my co-workers. Earlier I was introvert but now I talk to people, build rapport with everyone and give time to everybody".

Meditator 10 : [Male, 63 years, completed 3 - 10-day courses]

"My tolerance is increased and understanding of other person has become better... 'his misery boat is same as mine'. So we are there for life. Earlier if other professor is not wishing me 'good morning', ignoring me or not looking at me then I would have got upset 'how could he ignore me?' But it doesn't disturb me now. My ego has come down.

My wife is also a VM and Vipassana has given us a language 'Annichha' (impermanence). Arguments, disagreements and time taken to mull over has decreased considerably...it has come down from days to hours. Both have become more accommodating. Now, no major issues of disagreements. Have understood that small things are important. Also, shorter time for resolution is required within oneself. Both are equal and ambitions of both are equal...we are different human beings but we give each other space and within that we find a common ground.

Earlier I used to argue in social situations and would not give up my argument till I 'won'. But now I am not doing that at all. I listen."

\section{Discussion and Summary}

The results showed that meditators scored higher than non-meditators on all the five factors namely, Interpersonal Skills, Empathy, Self-Awareness, Equanimity and SelfConfidence (Table 3). This indicated that they were able to cope better with stress and adverse situations and their tendency to react was lower and were more empathetic. 
The values of t-Test validated the research objective (Table 4 , t-Test, $\mathrm{p}<0.001$ ). As discussed in the literature review, these qualities enhance communication skills leading to better teamwork and harmonious work relations [65], [51], [35], [76].

Thus, results indicated that the employees practicing VM were benefited as they were able to manage stressful adverse situations and interpersonal relations at work as well as in family, in a better and balanced manner and this paved the way for higher satisfaction with life. This shows that VM is a way of transforming the self and leading to increased equanimity and self-awareness [29]. Inner peace experienced in terms of better understanding, clarity of thought and self-control of oneself is a prerequisite to understand others [7]. As employees' empathy and interpersonal skills enhance, their ability to lead teams in an organisation also grow and this facilitates sustainable team development and higher productivity due to goal congruence.

The quantitative results obtained were corroborated by qualitative feedback collected from employees interviewed that they actually experienced the changes in terms of equanimity, non-reactivity, better communication, better interpersonal relations, selfconfidence, ability to manage stress effectively and better understanding of others.

\section{Conclusion}

For the organisations to flourish it is important to have efficient, productive and motivated employees. Harmonious personal and professional relations between employees, ability to handle stressful situations well will lead better employee performance and in turn better organisational performance leading to greater profitability and commercial success for the organisation. Also it will make the organisation an ideal place to work for. This research indicates that VM when internalised by employees paves the way to many positive personality characteristics. Therefore businesses that wish to improve employee team work, reduce work place conflicts, and employee goal congruence may adopt VM as an intervention strategy.

\section{References}

[1] Agrawal, R., \& Bedi, K. (2002). Transforming the Self: Exploring Effects of Vipassana on Delhi Police Trainees." Journal of Human Values 8.1: pp. 45-56.

[2] Atkins, P. W. B. \& Parker, S. K. (2012). Understanding individual compassion in organizations: The role of appraisals and psychological flexibility. Academy of Management Review, 37(4), pp. 524-546.

[3] Barnes, S., Brown, K. W., Krusemark, E., Campbell, W. K. \& Rogge, R. D. (2007). The role of mindfulness in romantic relationship satisfaction and responses to relationship stress. Journal of Marital and Family Therapy, 33: pp. 482-500.

[4] Beach, M. C., Roter, D., Korthuis, P. T., Epstein, R. M., Sharp, V., Ratanawongsa, N., Cohn, J., Eggly, S., Sankar, A., Moore, R. D., \& Saha, S. (2013). A multicenter study of physician mindfulness and health care quality. The Annals of Family Medicine, 11, pp. 421-428.

[5] Beckman, H. B., Wendland, M., Mooney, C., Krasner, M. S., Quill, T. E., Suchman, A. L., \& Epstein, R. M. (2012). The impact of a program in mindful communication on primary care physicians. Academic Medicine, 87, pp. 815-819.

[6] Birnie, K., Speca, M. \& Carlson, L. (2010). Exploring self-compassion and empathy in the context of mindfulness-based stress reduction (MBSR). Stress Health 26, pp. 359- 371. doi:10.1002/smi.1305 
[7] Böckler, A., Herrmann, L., Trautwein, F.M., Holmes, T., Singer, T. (2017). Know thy selves: learning to understand oneself increases the ability to understand others. Journal of Cognitive Enhancement. doi:10.1007/s41465-017-0023-6.

[8] Bodhi, Bhikkhu (1995). The Middle Length Discourses of the Buddha: A New Translation of the Majjhima Nikāya. Kandy, Sri Lanka: Buddhist Publication Society

[9] Brown, K. W., \& Ryan, K. M. (2003). The Benefits of Being Present: Mindfulness and its Role in Psychological Well Being. Journal of Personality \& Social Psychology, 84 (4), pp. 822-848.

[10] Butters, R. P. (2010). A Meta-Analysis of Empathy Training Programs for Client Populations. Doctoral Dissertation, Salt Lake City, UT: University of Utah. http://content.lib.utah.edu/u?/usetd2,152303

[11] Carson, J. W., Carson, K. M., Gil, K. M., \& Baucom, D. H. (2004). Mindfulness-based relationship enhancement. Behavior Therapy, 35: pp. 471-494.

[12] Chokhani R.M. (2001). Vipassana Meditation: An Insight-Oriented Therapy Based on the Buddha's Teachings; Paper presented at the South-East Asia Regional Conference on Scientific and Applied Psychology on Enhancing Human Potential, Mumbai.

[13] Condon, P., Desbordes, G., Miller, W. B. \& DeSteno, D. (2013). Meditation increases compassionate responses to suffering. Psychological Science, 24, pp. 2125-2127.

[14] Crescentini, C., \& Capurso,V. (2015). Mindfulness meditation and explicit and implicit indicators of personality and self-concept changes. Front. Psychol. 6:44. doi:10.3389/fpsyg.2015.00044

[15] Decety, J., \& Jackson, P. L. (2004). The functional architecture of human empathy. Behavioral and Cognitive Neuroscience Reviews, 3, pp. 71-100.

[16] Dekeyser, M., Raes, F., Leijssen, M., Leysen, S., \& Dewulf, D. (2008). Mindfulness skills and interpersonal behaviour. Personality and Individual Differences, 44, pp. 1235-1245.

[17] Desbordes, G., Gard, T., Hoge, E. A., Hölzel, B. K., Kerr, C., Lazar, S. W.,.. et al. (2015). Moving beyond mindfulness: defining equanimity as an outcome measure in meditation and contemplative research. Mindfulness 6, pp. 356-372. doi:10.1007/s12671-013-0269-8

[18] Dickinson, J., Friary, P. \& McCann C. M. (2016). The influence of mindfulness meditation on communication and anxiety: A case study of a person with aphasia. Aphasiology, 31 (9), pp. 1044-1058, DOI: $10.1080 / 02687038.2016 .1234582$

[19] Dienesch, R. M. \& Liden, R. C. (1986). Leader-member exchange model of leadership: A critique and further development. Academy of Management Review, 11, pp. 618-634.

[20] Eisenberg, N. (1986). Altruistic emotion, cognition and behaviour. Hillsdale, N J: Erlbaum.

[21] Epstein, N. B., \& Baucom, D. H. (2002). Enhanced cognitive-behavioural therapy for couples: A contextual approach. Washington, DC, US: American Psychological Association.

[22] Fleischman, P. R. (1991). Vipassana meditation: Healing the Healer: The Experience of Impermanence. Vipassana Research Institute.

[23] Fruzzetti, A. E. (1996). Causes and consequences: Individual distress in the context of couple interactions. Journal of Consulting and Clinical Psychology, 64 (6), pp. $1192-1201$.

[24] Fruzzetti, A. E. \& Iverson, K. M. (2004). Mindfulness, acceptance, validation, and 'individual' psychopathology in couples. In S. C. Hayes, V. M. Follette, \&M. M. Linehan (Eds.), Mindfulness and acceptance: Expanding the cognitive behavioral tradition. pp. 168 - 191. New York: Guilford Press

[25] Fry, L.W. (2003). Towards a theory of spiritual leadership, Leadership Quarterly, 14 (1), pp. 693723.

[26] Gazda, G. M., Ashbury, F. R., Balzer, F. J., Childers, W. C., \& Walters R. P. (1977). Human relations development: A manual for educators. Boston: Allyn \& Bacon, 232 pp.

[27] Giluk, T. (2009). Mindfulness, big five personality, and affect: a meta-analysis. Pers. mIndivid. Differ. 47, pp. 805-811. doi: 10.1016/j. paid.2009.06.026

[28] Goenka, S. N. (1980). Retrieved from Vipassana Research Institute: http://www.vridhamma.org/Art of living.

[29] Goenka, S. N. (1986). Removing the impurities within. Discourse for old students, Lakkhamsi Nappu Hall, Mumbai, July 20, 1986, Part 3. Vipassana Newsletter, Vol. 27, No. 7, 9 July 2017.

[30] Goenka, S.N. (2001). Was the Buddha a Pessimist? Vipassana Research Institute, Igatpuri. Quarterly, Vol. 4 No. 3, pp. 39-59. 
[31] Good, D. J., Lyddy, C. J., Glomb, T. M., Bono, J. E., Brown, K. W., Duffy, M. K., Baer, R. A., ... (2016).Contemplating mindfulness at work: An integrative review. Journal of management 42 (1), pp. $114-142$

[32] Gupta, S. (1997). Productivity and Harmony through Vipassana. Indira Gandhi National Open University, School Of Management Studies, New Delhi.

[33] Hargie, O. (2016). Skilled Interpersonal Communication Research, Theory and Practice. Routledge, London. eBook ISBN 9781317584568

[34] Hart, W. (1987). The Art of Living: Vipassana Meditation as Taught by S N Goenka. New York: Harper \& Row.

[35] Hoge, E. A., Guidos, B. M., Mete, M., Bui, E., Pollack, M. H., Simon, N. M., Dutton, M. (2017). Effects of mindfulness meditation on occupational functioning and health care utilization in individuals with anxiety. Journal of Psychosomatic Research, 95, pp. 7-11

[36] Hölzel, B. K., Lazar, S. W., Gard, T., Schuman-Olivier, Z., Vago, D. R., \& Ott, U. (2011). How does mindfulness meditation work? Proposing mechanisms of action from a conceptual and neural perspective. Perspect. Psychol. Sci. 6, pp. 537-559. doi: 10.1177/1745691611419671

[37] Jackson, S., Bijstra, J., Oostra, L., \& Bosma, H. (1998). Adolescents' Perceptions of Communication with Parents Relative to Specific Aspects of Relationships with Parents and Personal Development. Journal of Adolescence, 21, pp. 305-322. http://dx.doi.org/10.1006/jado.1998.0155

[38] Jinadasa, M. (2017). Indian Buddhist Philosophy for the Modern Theory of Communication and Public Relations. Paper presented at 25th May 2017 on the Preconference: Tryst with Democracy: 70 years of Media in Independent India - successes, Challenges, Interventions. International Communication Association. (ICA) Annual conference 2017, University of California, San Diego (UCSD), USA.

[39] Jones, S. M., Bodie, G. D., \& Hughes, S. D. (2016). The Impact of Mindfulness on Empathy, Active Listening, and Perceived Provisions of Emotional Support. Research Article https://doi.org/10.1177/0093650215626983

[40] Joshi, S. S. (1994). Effect of Vipassana on the Work Environment. Vipassana Research Institute.

[41] Kabat-Zinn, J., Massion, A. O., Kristeller, J., Peterson, L. G., Fletcher, K. E., Pbert, L., et al. (1992). Effectiveness of a meditation-based stress reduction program in the treatment of anxiety disorders. American Journal of Psychiatry, 149, pp. 936-943.

[42] Kabat-Zinn, J. (1996). Mindfulness meditation: What it is, what it isn't, and its role in health care and medicine. In Y. Haruki, Y. Ishii, \& M. Suzuki (Eds.). Comparative and Psychological Study on Meditation, pp. 161-170. Netherlands: Eburon Publishers.

[43] Kadziolka, M.J., Di Pierdomenico, EA. \& Miller, C.J. (2016). Trait-Like Mindfulness Promotes Healthy Self-Regulation of Stress. Mindfulness, 7(1), pp. 236-245. https://doi.org/10.1007/s12671-0150437-0

[44] Kirby, J. N. (2017), Compassion interventions: The programmes, the evidence, and implications for research and practice. Psychology and Psychotherapy, Theory Research and Practice, 90, pp. 432-455. doi:10.1111/papt.12104

[45] Knowles, J. H., Manusov, V. \& Crowley, J. (2015). Minding Your Matters Predicting Satisfaction, Commitment, and Conflict Strategies Trait Mindfulness. Interpersonal, ISSN 1981-6472, 9 (1), pp. $44-$ 58

[46] Kornfield, J. (2002). A Path with Heart. Rider Penguin Publishing House: London.

[47] Kothari, C. R. \& Garg, G. (2014). Research Methodology. New Age International Publishers.

[48] Lippold, M. A., Duncan, L. G., Coatsworth, J. D., Nix, R. L., \& Greenberg, M.T. (2015). Understanding How Mindful Parenting May Be Linked to Mother-Adolescent Communication. Journal of Youth and Adolescence, 44 (9), pp. 1663-1673.

[49] Long, E. C., \& Christian, M. S. (2015). Mindfulness buffers retaliatory responses to injustice: A regulatory approach. Journal of Applied Psychology, 100, pp. pp. 1409-1422.

[50] Marta, E. (1997). Parent-adolescent interactions and psychosocial risk in adolescents: an analysis of communication, support and gender. Journal of Adolescence, 20(5), pp. 473-487 
[51] Mathieu, J. E., Heffner, T. S., Goodwin, G. F., Salas, E., \& Cannon-Bowers, J. A. (2000). The influence of shared mental models on team process and performance. Journal of Applied Psychology, 85, pp. 273-283

[52] Montemayor, R. (1986). "Family Variation in Parent-Adolescent Storm and Stress." Journal of Adolescent Research, 1, pp. 15-31.

[53] Montero-Marin, J., Puebla-Guedea, M., Herrera-Mercadal, P., Cebolla, A., Soler, J., Demarzo, M., García-Campayo, J. (2016). Psychological Effects of a 1-Month Meditation Retreat on Experienced Meditators: The Role of Non-attachment. Frontiers in Psychology, 7, 1935. http://doi.org/10.3389/fpsyg.2016.01935

[54] Nanamoli [Thera]. (1976). Trans. The Path of Purification. 2 vols. $3^{\text {rd }}$ edn. Kandy: Buddhist Publication Society.

[55] Nyanaponika, Thera. (1973).The Heart of Buddhist Meditation: Satipatthna: A Handbook of Mental Training Based on the Buddha's Way of Mindfulness .Weiser Books.

[56] Oxford University Press. (1980). The Compact Edition of the Oxford English Dictionary. England: Oxford University Press.

[57] Parihar, D. (2004). Vipassana in Government. Vipassana Research Institute.

[58] Pradhan, S., Ajithkumar, V. V. \& Singh M. (2016). Effect of Vipassana Meditation on Mindfulness and Life satisfaction of employees. International Journal of Research in Commerce \& Management (IJRCM), 7 (3), 11-16. ISSN 0976-2183.

[59] Pradhan, S. \& Ajithkumar V. V. (2017a). Vipassana Meditation: An Effective Practice for Positive Changes in Employees. Skyline Business Journal. XIII (1), pp. 45-59. (2017-2018). ISSN 1998-3425.

[60] Pradhan, S. \& Ajithkumar V. V. (2017b). The Impact of Vipassana Meditation Practices on Psychological Wellbeing of Employees. International Journal of Applied Business and Economic Research, 15, No.16 (Part-II). ISSN : 0972-7302. http: www.serialsjournals.com

[61] Quaglia, J. T., Goodman, R. J. \& Brown, K. W. (2015). From mindful attention to social connection: The key role of emotion regulation. Cognition and Emotion, 29, pp. 1466-1474.

[62] Razzino, B. E., New, M., Lewin, A., \& Joseph, J. (2004). Need for and use of mental health services among parents of children in a head start program. Psychiatric Services, 55(5), pp. 583-586

[63] Reb, J., Narayanan, J., \& Chaturvedi, S. (2014). Leading mindfully: Two studies on the influence of supervisor trait mindfulness on employee well-being and performance. Mindfulness, 5, pp. 36-45.

[64] Riesch, S. K., Anderson, L. S., \& Krueger, H. A. (2006). Parent-Child Communication Processes: Preventing Children's Health-Risk Behavior. Journal for Specialists in Pediatric Nursing, 11(1), pp. 4156. http://dx.doi.org/10.1111/j.1744-6155.2006.00042.x

[65] Rogers, C. (1961). On Becoming a Person. Boston: Houghton Mifflin.

[66] Rosenberg, M. (1987). A Model for Nonviolent Communication. Philadelphia: New Society

[67] Saavedra, M. C., Chapman, K. E., \& Rogge, R. D. (2010). Clarifying links between attachment and relationship quality: Hostile conflict and mindfulness as moderators. Journal of Family Psychology, 24: 380-390.

[68] Sahdra, B., Shaver, P., \& Brown, K. (2010). A scale to measure nonattachment: a buddhist complement to western research on attachment and adaptive functioning. J. Personal. Assess. 92, pp. 116-127.doi:10.1080/002238909034 25960

[69] Schellekens, M.P.J., Karremans, J.C., van der Drift, M.A. et al. (2017). Mindfulness, 8 (2), pp. $325-$ 336. https://doi.org/10.1007/s12671-016-0602-0

[70] Shah, J. (1994). Vipassana and Business Management. In Vipassana: Its' Relevance to the Present World. Vipassana Research Institute.

[71] Shek, D. T. L., Lee, T. Y., Siu, A., \& Lam, C. M. (2006). Qualitative evaluation of the Project P.A.T.H.S. based on the perceptions of the program participants. The Scientific World Journal: TSW Holistic Health \& Medicine, 1, pp. 290-299.

[72] Shumow L. \& Lomax R. (2002). Parental self-efficacy: Predictor of parenting behavior adolescent outcomes. Parenting, Science and Practice, 2, pp. 127-150.

[73] Soler, J.,Valdepérez, A., Feliu-Soler, A., Pascual, J. C., Portella,M. J., Martín- Blanco, A., ..et al. (2012). Effects of the dialectical behavioral therapy- mindfulness module on attention in patients with borderline personality disorder. Behav.Res.Ther. 50, pp. 150-157.doi:10.1016/j.brat.2011.12.002 
[74] Soler, J., Elices, M., Pascual, J. C., Martín-Blanco, A., Feliu-Soler, A., Carmona, C., et al. (2016). Effects of mindfulness training on different components of impulsivity in borderline personality disorder: results from a pilot randomized study. Borderline Personal. Disord. Emot. Dysregul. 3:1. doi:10.1186/s40479-015-0035-8

[75] Spadaro, K. C. \&Hunker, D. F. (2016). Exploring the effects of an online asynchronous mindfulness meditation intervention with nursing students On Stress, mood, And Cognition: A descriptive study. Nurse Education Today, 39, pp. 163-169.

[76] Singh G., Maurya A., \& Jain V. (2017) Spirituality in Indian Organizations. In: Nandram S., Bindlish P. (eds) Managing VUCA Through Integrative Self-Management. Management for Professionals. Springer, Cham. https://doi.org/10.1007/978-3-319-52231-9_12

[77] Stepien, K. A., \& Baernstein, A. (2006). Educating for empathy. A review. Journal of general internal medicine, 21(5), pp. 524-30.

[78] Tanay, G., Lotan, G., \& Bernstein, A. (2012). Salutary proximal processes and distal mood and anxiety vulnerability outcomes of mindfulness training: A pilot preventive intervention. Behavior Therapy, 43, pp. 492-505

[79] Thomas, G. (1977). Leader Effectiveness Training. Widen Books.

[80] Tran, U.S., Cebolla, A., Glück,T. M., Soler, J., García-Campayo, J., \& vonMoy, T. (2014). The serenity of the meditating mind: A cross-cultural psychometric study on a two-factor higher order structure of mindfulness, its effects, and mechanisms related to mental health among experienced meditators. PLOS ONE 9:e110192. doi:10.1371/journal.pone.0110192

[81] VanDam, N.T., Sheppard, S.C., Forsyth, J.P. \& Earleywine, M. (2011). Self- compassion is a better predictor than mindfulness of symptom severity and quality of life in mixed anxiety and depression. $J$. Anxiety Disord. 25, pp.123-130. doi:10.1016/j.janxdis.2010.08.011

[82] Wachs, K. \& Cordova, J. V. (2007). Mindful relating: Exploring mindfulness and emotion repertoires in intimate relationships. Journal of Marital and Family Therapy, 33: 464-481.

[83] Wallace, B. (2006). The Attention Revolution: Unlocking the Power of the Focused Mind. Somerville, MA: Wisdom Publications

[84] Walsh, F. (1998). Families in later life: Challenge and opportunities. In B. Carter \& M. McGoldrick (Eds.), The expanded life cycle pp. 307-326. Needham Heights, MA: Allyn \& Bacon.

[85] Walsh, R. (1999). Essential spirituality: The seven central practices. New York: Wiley \& Sons.

[86] Zalta, A., (2015). Buddhist solutions(s) for conflict transformation: the application of Buddhist paradigms for understanding causes and consequences of conflict(s). Journal of the World Buddhist University. 11(1), pp. 68-78 